Article

\title{
Dynamical Trust and Reputation Computation Model for B2C E-Commerce
}

\section{Bo Tian ${ }^{1, *}$, Kecheng Liu ${ }^{2}$ and Yuanzhong Chen ${ }^{1}$}

1 School of Information Management \& Engineering, Shanghai University of Finance and Economics, Shanghai 200433, China; E-Mail: chenyz@mail.shufe.edu.cn

2 Informatics Research Centre, University of Reading, Reading RG6 6UD, UK; E-Mail: k.liu@henley.ac.uk

* Author to whom correspondence should be addressed; E-Mail: youngtb@sina.com; Tel./Fax: +86-21-6590-0518.

Academic Editor: Carlo Cattani

Received: 9 September 2015 / Accepted: 19 October 2015 / Published: 27 October 2015

\begin{abstract}
Trust is one of the most important factors that influence the successful application of network service environments, such as e-commerce, wireless sensor networks, and online social networks. Computation models associated with trust and reputation have been paid special attention in both computer societies and service science in recent years. In this paper, a dynamical computation model of reputation for B2C e-commerce is proposed. Firstly, conceptions associated with trust and reputation are introduced, and the mathematical formula of trust for B2C e-commerce is given. Then a dynamical computation model of reputation is further proposed based on the conception of trust and the relationship between trust and reputation. In the proposed model, classical varying processes of reputation of B2C e-commerce are discussed. Furthermore, the iterative trust and reputation computation models are formulated via a set of difference equations based on the closed-loop feedback mechanism. Finally, a group of numerical simulation experiments are performed to illustrate the proposed model of trust and reputation. Experimental results show that the proposed model is effective in simulating the dynamical processes of trust and reputation for B2C e-commerce.
\end{abstract}

Keywords: dynamical trust; direct trust; reputation computation; $\mathrm{B} 2 \mathrm{C}$ e-commerce 


\section{Introduction}

The development of the Internet provides small and medium enterprises (SMEs) new opportunities to extend their operations. However, new challenges also arise as a result of the virtual characteristics of the Internet. The Internet easily broadcasts information. However, websites of SMEs have relatively low degrees of trust and reputation [1-5]. Trust is one of the most important factors that influences the successful application of network service environments such as e-commerce, wireless sensor networks, and online social networks, and so on [6-8]. How to improve the degree of trust and establish a reputation in online marketplaces is critical for these enterprises [1,9-12]. Computation models associated with trust and reputation are becoming focal issues in computer societies, management societies, and service science in recent years [13-25]. In this paper, a new computation model of dynamical trust and reputation for $\mathrm{B} 2 \mathrm{C}$ e-commerce is proposed. The proposed framework simulates the dynamical processes of trust and reputation evaluation for $\mathrm{B} 2 \mathrm{C}$ e-commerce by using a mathematical model.

One principal role of the Internet is information dissemination and communication. E-commerce is defined as transactions of products and services over the Internet. The prototype of e-commerce is Electronic Data Interchange (EDI) [26,27]. With the development of information exchange techniques and the popularization of the Internet, Business-to-Business (B2B) e-commerce is exceeded by Business-to-Consumer (B2C) e-commerce in the 1990s [5,28,29]. Commercial data exchange in EDI used the private value-add-network between those who are familiar with and trust each other. However, the situation changed in $\mathrm{B} 2 \mathrm{C}$ e-commerce which is based on the Internet. On one hand, in the service-oriented Internet field, many kinds of e-services can be provided for different types of users. On the other hand, many users are reluctant to purchase products or services over the Internet. For example, only five percent of active Internet users made purchases via the Internet in Hong Kong over the last ten years [30]. A report made by China Internet Network Information Center (CINIC) of China revealed that only about 40 percent of Internet users in China had the experience of purchasing via the Internet in 2014 [31]. The lack of trust is still one of the most important reasons for users not purchasing over the Internet [14,15,22,32-37]. This phenomenon is not surprising when the characteristics of the Internet are considered. The Internet is known to be a loosely coupled system. The Internet is designed primarily as a medium of cooperation and information sharing. Furthermore, the Internet is not originally designed as a commerce environment [38]. Thus, trust is hard to achieve and maintain. The reasons behind the lack of trust in B2C e-commerce are complex. First of all, service clients cannot interact with products and service providers directly, and they are also unfamiliar with online added services. The credibility of online information is weak [15,39]. Security and privacy of key pieces of information that consumers provide through the Internet are also important issues for consumers $[8,40,41]$. In such an uncertain environment, trust becomes one of the most important factors in the development of Internet services such as e-commerce $[22,42]$. Indeed, the Internet provides maximal convenience in the information era. The number of total financial transactions made via the Internet has been increasing. The problems associated with trust are those derived from certain techniques, and the human element in e-commerce can be solved step by step. In terms of the evaluation of trust and reputation in regards to the Internet, many practical trust evaluation systems focus mainly on Peer-to-Peer networks such as $\mathrm{C} 2 \mathrm{C}, \mathrm{B} 2 \mathrm{~B}$ e-commerce, and B2C e-commerce [43-48]. As for B2C e-commerce, some trust models and reputation evaluation methods have been put forward $[11,49,50]$. Various researchers have paid special attention to 
computation models of trust and reputation for B2C e-commerce in recent years [14-16,25,51-54]. It is important to take into account the dynamical factor in the processes of trust development and reputation evaluation. This paper proposes new dynamical trust and reputation computation models for B2C e-commerce.

The remainder of this paper is organized as follows. The notion and meanings of trust for B2C e-commerce in network environments are reviewed in Section 2. The components and mathematical formula of dynamical trust for $\mathrm{B} 2 \mathrm{C}$ e-commerce are discussed in Section 3. The main factors that influence the dynamical trust in $\mathrm{B} 2 \mathrm{C}$ e-commerce are analyzed. Then a computation model of reputation is proposed based on the relationship between trust and reputation in $\mathrm{B} 2 \mathrm{C}$ e-commerce in Section 4. In the proposed model, the main variation processes of reputation in $\mathrm{B} 2 \mathrm{C}$ e-commerce are discussed. Iterative trust and reputation computation models are expanded based on the trust and reputation models. A group of simulation experiments are performed to illustrate the proposed model in Section 5. Finally, conclusions are drawn in Section 6.

\section{State-Of-The-Art}

Trust is an important component of different social relationships such as interpersonal relations, economical relations, and so on. The conception of general trust has been researched in different academic disciplines such as philosophy, psychology, management, and economics [14,19,22,36,37,55]. Trust in the Internet has some common and different characteristics with traditional theories of trust. To begin with, general research on trust is examined before the particularity of online trust is analyzed, with special emphasis on trust in $\mathrm{B} 2 \mathrm{C}$ e-commerce.

Ancient philosophers studied trust as part of human nature, and modern philosophers mainly study interpersonal trust and the morality of trust relationships. Political philosophers look at trust as having social value and benefits. Psychology mainly investigates interpersonal trust. Psychologists consider interpersonal trust to be an important concept in psychology and vital to personality development, cooperation, institutions, and society [56]. In management, trust is studied in organizational contexts. Trust is identified as one control mechanism that enables employees to work together more productively and effectively [57]. As for economics and marketing, trust is one of the components of consumer relation management (CRM) [8,22,58]. Disagreements as to definitions of trust occur for two reasons. First, trust is an abstract concept and is often used interchangeably with relative concepts such as reputation, credibility, and confidence. Second, trust is a multi-faceted concept that incorporates cognitive, emotional, and behavioral components.

Following the above, trust and reputation models for the Internet environment will now be reviewed. Computational trust and reputation models in virtual societies were reviewed by Jordi and Carles [55]. The authors listed some typical criteria by which main computational trust and reputation models are classified. The authors noted that reliability measures of the calculated trust and reputation values are not mentioned in previous methods, and few models proposed the links between trust and reputation. However, as we know, reputation is one of the most important ways to help build trust. Different trust and reputation models for Internet mediated service provisions were surveyed by Jøsang, Ismail, and Boyd [4]. The authors discussed the notion of trust, the relationship of trust and reputation, and research agendas for trust and reputation. Different reputation network architectures are described. Reputation 
computation methods and some well-known commercial reputation systems are surveyed. Main problems and solutions of these models and systems are also mentioned. Main approaches to model reputation systems were reviewed by Gutowska, Sloane and Buckley [21]. The authors presented a new reputation model for the distributed reputation system in $\mathrm{B} 2 \mathrm{C}$ e-commerce applications. The model considered several aspects that influence trust and reputation such as age of ratings, transaction value, credibility of referees, number of malicious incidents, and unfair ratings.

Additionally, other aspects that affected online trading decisions such as trust-mark seals, payment intermediaries, privacy statements, security, and privacy strategies were also discussed [48-51]. It is understood that the Internet provides opportunities at the same time as presenting numerous threats and risks. Reputation evaluation is one way to minimize threats. Reputation evaluation is usually performed through feedback reviews subsequent to transactions. However, the quality of feedback degraded the quality of reviews. An evaluation method for reviewing quality in terms of multiple metrics was presented by Li and Li, Du and Tian [53]. Based on the filtered reviews, a service reputation evaluation was proposed by Cho, Kwon and Park [18]. A trust management framework that is event-driven and rule-based in service-oriented computing environments was proposed by Wang, Lin and Wong [52]. The paper proposed trust evaluation metrics and trust computation formulas. The incremental characteristics of the trust establishment process were embodied in the proposed model. Reputation ranks were determined by a fuzzy-logic based approach in which new service providers and old ones were differentiated [25]. Service users are important information sources for the reputation of service providers, and transaction-feedback is used as the quality indicator for trust building in e-commerce. Unfair or incorrect information from unreliable or malicious users have significant negative effects on the fairness and objectivity of reputation evaluation. Therefore, the collaborative filtering method is used in reputation systems by different researchers in order to detect and isolate unfair or inaccurate information provided by unreliable or malicious users $[18,20]$. In recent years, probability-based approaches such as the Bayesian model and the Dirichlet model $[6,17,22,59]$ are derived into trust and reputation computation. Online trust and reputation issues for $\mathrm{B} 2 \mathrm{C}$ e-commerce have been investigated by researchers of different disciplines, yet there are further issues that remain to be solved.

(1) There are some practical reputation rating systems of $\mathrm{B} 2 \mathrm{C}$ e-commerce such as taobao (www.taobao.com), dangdang (www.dangdang.com) and 360buy (www.360buy.com). In these reputation evaluation systems, ratings and reviews of users are stored. The reputation rankings of these systems are mainly based on simple means algorithms. Theoretical research on the reputation systems is also put forward [9,18,59-61]. However, the rating algorithms are particularly simple. We know that reputation is a long-term process during which trust is established. How to describe the characteristics of trust and reputation is one goal for this research.

(2) The temporal relationship of trust and reputation are not considered in previous research projects [14-16,18,22,52,53]. In terms of both real life and theory, the reason that certain things or service providers are trusted may be their positive reputation. On the other hand, reputation is built via word-of-mouth and trust. So a reputation computation model for B2C e-commerce will be investigated by trust values from reviewers. Reputation is aggregated by several aspects, such as trust values, different reviewers, different time, and different transactions. The temporal relationship of trust and reputation is 
included in our proposed computation model. The closed-loop iterative computation model is established, which is based on the conceptions of local trust and overall reputation.

(3) How to design a fair and optimal reputation management system is still an open problem for both practical usages of website services, such as B2C e-commerce and theoretical research of the reputation system. Centralized and distributed management architectures are two design options [52,55,60]. In centralized reputation management systems, reviews of service clients are independent of service providers [2,52]. We adopt centralized management architecture in the proposed reputation computation model. The dynamical trust computation model is put forward, in which different aspects of various factors are considered. A reputation evaluation system is further established by fusing trust values. An iterative trust and reputation computation model is further proposed. The proposed evaluation method is intended to be relatively fair and objective.

$\mathrm{B} 2 \mathrm{C}$ e-commerce is defined as consumers purchasing products and services via the Internet, otherwise known as online shopping. Trust in B2C e-commerce is associated with consumer experiences, asymmetry of information, interval of space and time of transactions, and transaction risk $[62,63]$. The conception of trust in $\mathrm{B} 2 \mathrm{C}$ e-commerce can be outlined as follows. Trust in $\mathrm{B} 2 \mathrm{C}$ e-commerce is the subjective psychology status of consumers that relies on the promise made by online firms, their websites, or transaction environment under certain societal and technical circumstances. The psychology of perceptive reliance is developed from previous customer practices. The objective of the psychology of perceptive reliance is to reduce transaction risks and the uncertainty that come from information asymmetry, time-space interval and other factors. Reputation systems collect, process, and aggregate information about participants or services, which can help future users make optimal decisions [61]. Systems of good reputation should encourage trustworthy behaviors and punish dishonest participation [50]. Following, the dynamical trust computation model for B2C e-commerce will be formulated, and the relationship of trust and reputation will be discussed further. Based on the logical relationship of trust and reputation, the iterative trust and reputation computation model is derived.

\section{Means and Mathematical Formula of Trust}

Characteristics of trust for B2C e-commerce are firstly analyzed in this section. Then, components of trust in $\mathrm{B} 2 \mathrm{C}$ e-commerce are discussed. Mathematical formula of dynamical trust for B2C e-commerce is further derived.

\subsection{Characteristics of Trust for B2C E-Commerce}

In general, trust is associated with the trustor and trustee; vulnerability arises from uncertainty and perceived risks, while actions are encouraged by trust. Trust in B2C e-commerce is a particular form of trust. When trust is discussed in the network environment, some new characteristics of the Internet and online shopping should be included in the trust system.

In trust relationships of $\mathrm{B} 2 \mathrm{C}$ e-commerce in network environments, the trustors are usually service clients or buyers who browse e-commerce websites and make transaction decisions. Trustees are generally online service providers and e-commerce websites. Due to the complexity and ambiguity of online information and virtual environments, higher degrees of vulnerability occur when compared with traditional trust situations. Because of information asymmetry, time-space intervals, the openness of the 
Internet, and weakness of information techniques, trust is more important in virtual environments such as $\mathrm{B} 2 \mathrm{C}$ e-commerce than in traditional trades. The attitude of the trustor towards society and technology differs for each individual. Therefore, trust in $\mathrm{B} 2 \mathrm{C}$ e-commerce is a subjective conception and the characteristics of different kinds of service clients or buyers will be considered in our proposed computation model. Trust is closely associated with reputation in both a virtual environment and real life. How service providers' reputations influence trustors' decisions will also be considered in the proposed trust computation model. If service clients or buyers trust a website, he or she will deduce the trust status of the online service provider, and make purchase decisions accordingly. The components of the trust system will be derived from the above characteristics of trust in $\mathrm{B} 2 \mathrm{C}$ e-commerce.

\subsection{Components of Trust for B2C E-Commerce}

Components of traditional trust have heuristic roles when we draw the component system chart of trust in B2C e-commerce. Personality, environment, and risk are three factors that influence the establishment of trust [53]. Three attributes namely benevolence, competence, and integrity constitute the main elements of trustworthiness, which is thought of as an antecedent of trust [50]. Predictability is also an important component of trust [56]. Belief is regarded as an important mental experience in trust [62]. The components of trust in $\mathrm{B} 2 \mathrm{C}$ e-commerce are related to not only the participants named buyers and the online service provider, but also the circumstances containing Internet-related techniques and social cultures [62]. There are four main antecedents that influence the trust of service clients in B2C e-commerce: trustworthiness of the Internet merchant, trustworthiness of the Internet as a shopping medium, infrastructural factors such as security, third-party certification, and other factors such as company size and demographic variables.

There are also some conclusive remarks regarding online trust components. Trust was formulated to have six dimensions: consumer behavior, institutional, information, product, transaction, and technology [50]. Trust was investigated from multi-dimensional antecedent components namely the beliefs of integrity, ability, and benevolence [64]. In B2C e-commerce, integrity is the belief that companies act in a consistent, reliable, and honest manner while keeping their promises. Ability refers to the belief that the company has the ability to fulfill their promises. Benevolence is the belief in the ability of companies to care about consumer interests and be concerned for the welfare of their customers. Trust in B2C e-commerce is based on the confidence of consumers. Both belief and confidence are derived from the uncertainties and risks involved in the online transaction environment. Following three aspect components of trust named trustee, trustor, and the transaction environment in B2C e-commerce are discussed separately.

The trustee is the e-commerce website, merchant, and online service provider. This includes components such as branding, offline presence, faith, cooperation, familiarity, benevolence, company history, merchant quality, price, and website quality in terms of convenience, usability, efficiency, reliability, privacy and security. Components of the trustor include the disposition to trust, purchase history, attitude towards online shopping websites, attitude towards information techniques, personal values, age, education, gender, and subjective perceptive risk. Environmental components include technique and social factors. Components concerning the techniques of environments include privacy, security, transparency, credibility of information, Internet-relative techniques, information techniques, 
encryption, and third party certification. Social components of environments include policy, law, morality, and culture.

\subsection{Direct Trust and Indirect Trust}

Components that influence trust in $\mathrm{B} 2 \mathrm{C}$ e-commerce can be divided into direct and indirect factors. Factors that influence direct trust and indirect trust will be discussed here separately. Further, a dynamical computation model of trust for $\mathrm{B} 2 \mathrm{C}$ e-commerce is established based on the primary direct trust computation model.

When we analyze the factors influencing direct trust in $\mathrm{B} 2 \mathrm{C}$ e-commerce in a simple situation, service clients or buyers are assumed to browse the website and make purchases without any transcendental knowledge about the online service providers in advance. Environments of technique and society provide the surrounding in which the transactions occur. From the service clients' or buyers' point of view, the disposition to trust is developed throughout their whole lives. As for the service provider's website, these websites that the service clients or buyers face are main tools that can persuade him or her to make their decision. Therefore, the design of the website is crucial. Convenience, usability, efficiency, and reliability can be important characteristics of websites to enable them to ensure the integrity, privacy, and security of both themselves and the online service provider. Additionally, merchant quality, price, and service are also very important in terms of increasing the trust of the consumer. In terms of the online service provider, information about the provider of the website should be dependable. Both the offline presence and the history of the provider should be addressed. Brand, faith, cooperation, familiarity, and benevolence of the provider should also be embodied in the website of the provider.

Factors that influence indirect trust in B2C e-commerce also arise from three different entities of trust. When service clients or buyers wish to make a purchase from an online firm, the decision will be influenced by indirect trust information taken from other sources. Environments of technique and society in B2C e-commerce are exterior factors. Disposition and attitude towards online or offline trust of the consumer are formed gradually throughout his or her life. Factors that influence indirect trust are mainly focused on the reputation of service providers and the recommendation of online service clients and other service clients or advertisements. The dynamical trust computing model of B2C e-commerce is established based on the primary direct trust. Total trust and reputation computation models will be further proposed.

\subsection{Direct Trust Model}

Based on the above analysis, the direct trust computation function $f_{\text {dir }}$ can be defined as

$$
f_{\text {dir }}(t)=f\left(T_{e}(t), T_{c}(t), T_{p}(t)\right)
$$

where $T_{e}(t), T_{c}(t)$ and $T_{p}(t)$ are trust value concerning environments, service clients, and the service provider, the values of which are limited in domain [0,1], and $t$ is denoted as time. If a simple multiple function is used to derive the explicit form of Equation (1), the direct trust evaluation function $f_{\text {dir }}$ can be written as

$$
\left.f_{\text {dir }}(t)=T_{e}(t) * T_{c}(t) * T_{p}(t)\right)
$$


Following function $T_{e}(t), T_{c}(t)$ and $T_{p}(t)$ are defined separately based on the factors that influence values of trust. We notice that $T_{e}(t)$ is related with the attitude of society towards techniques and societal factors. The change of attitude towards techniques and societal factors is very slow. So the values of $T_{e}(t)$ is assumed to be some constant. $T_{c}(t)$ is related to service clients. The different backgrounds of service clients, such as disposition to trust, attitude, and personal values can also be viewed as a constant. In our simulations, three classical types of service clients, which are risk taking, cautious, and conservative, are discussed. $T_{p}(t)$ is related to the service provider, which includes the factors of websites, merchants, and online firms. The changes of values of dynamical direct trust are mainly dependent on the changes of values of $T_{p}(t)$. Two situations those the values of $T_{p}(t)$ change are simulated, and these are the procedures of improvement and descent. In the process of improvement of the values of $T_{p}(t)$, there are three main stages: establishment stage, improvement stage, and stabilization stage. The derivative function of $T_{p}(t)$ can be simulated by the following equation [52]

$$
\frac{d T_{p}(t)}{d t}=\alpha\left(1-\left(\frac{e^{\alpha t}-e^{-\alpha t}}{e^{\alpha t}+e^{-\alpha t}}\right)^{2}\right)
$$

where $\alpha$ is the parameter of the derivative function of $T_{p}(t)$. From Equation (3), $T_{p}(t)$ can be solved as

$$
T_{p}(t)=\frac{e^{\alpha t}-e^{-\alpha t}}{e^{\alpha t}+e^{-\alpha t}}
$$

We see that $T_{p}(t)$ is the transformation of Hyperbolic Tangent. The images of $T_{p}(t)$ and its derivative function shows that in the trust establishment stage, values of trust do not increase rapidly. In the improvement stage, however, values of trust do increase rapidly. In the stabilization stage, values of trust do not increase rapidly. Therefore, Equation (4) simulates the processes of the improvement of trust values. The derivative function of the process of the decrement of values of $T_{p}(t)$ can also be similarly simulated by following equation

$$
\frac{d T_{p}(t)}{d t}=-\alpha\left(1-\left(\frac{e^{\alpha t}-e^{-\alpha t}}{e^{\alpha t}+e^{-\alpha t}}\right)^{2}\right)
$$

The corresponding function $T_{p}(t)$ can be solved as

$$
T_{p}(t)=\frac{e^{-\alpha t}-e^{\alpha t}}{e^{-\alpha t}+e^{\alpha t}}
$$

There are two stages of the decrement processes. In the first stage, values of $T_{p}(t)$ fall quickly. Then, the values of $T_{p}(t)$ will be relatively low slowly. Concrete numerical simulations of the trust computation model will be discussed in Section 5. The reputation computation model based on trust will be further discussed.

\section{Iterative Trust and Reputation Computation Model}

Trust is divided into direct trust and indirect trust. In Section 3, the primary direct trust computation model is established. Indirect trust refers to the reputation of service providers and recommendation of other service clients. The total trust and reputation computation model is investigated in this section. 


\subsection{Reputation System in B2C E-Commerce}

Trust in a service-oriented network environment is the subjective psychological status of the service clients or buyers, and relies on the promise made by online service providers. The aim of developing trust is to reduce transaction risks and uncertainties. Reputation systems collect, process, and aggregate trustworthy information regarding participants or services which help future users make optimal decisions. The role of trust is to nurture and sustain reputations, which is essentially a trust-building process. In network environments, service providers earn and retain trust via reputations. Without trust, a good reputation will erode. As a child is the father of a man, trust begets reputation. Loss of trust can damage a reputation. Reputation is a close relative of trust, yet they are not the same. Therefore, while a reputation may be trustworthy, it generally consists of a whole range of characteristics other than trust. Online service providers can develop and sustain reliable reputations via the processes of building trust.

There are two types of reputation system architectures in service-oriented network environments in which different trust ratings are gathered and stored [52]. These are referred to as centralized and distributed architectures. In centralized reputation architectures, the management of trust and reputation in network environments is based on centralized trust databases. Further, trust information regarding the performance of participants is collected, stored, and computed by a third central reputation authority. Reputation rankings and scores are available publicly, and service clients and users can consult with these for their next round of transactions. Such reputation systems include taobao, dangdang, and 360buy. Distributed reputation systems have no central reputation authority to submit their reputation ratings. Each client collects ratings from other participants, and each client records their opinion regarding their transactions with the service providers. When a client desires knowledge of the reputation of a potential transaction partner or service provider, he or she needs to obtain ratings from other clients who have already completed transactions with the same service provider and thus calculate the reputation status based on the score ratings. Such reputation systems are reputation architectures in $\mathrm{C} 2 \mathrm{C}$ e-commerce and P2P networks. Reputation system architecture can also be classified as bidirectional or unidirectional [53]. In bidirectional architecture, all users can be both service providers and service clients. In the case of unidirectional architecture, service providers and their products are rated by service clients. The proposed reputation system for B2C e-commerce based on the relationship of trust and reputation is centralized and is unidirectional in terms of its architecture, which can be illustrated in Figure 1. The trust status and reviews of the service provider provided by the service clients are collected, stored, and computed by a third central authority. Further, reputation computation results are performed by the values of trust reviews, which can be consulted within the next round of transactions.

\subsection{Reputation Computation Model}

As the proposed reputation system for $\mathrm{B} 2 \mathrm{C}$ e-commerce is based on the trust review records of other service clients or buyers, the trust value computation process for different types of service clients is discussed first. Thereafter, the aggregated reputation computation model is proposed which integrates all different trust values. From Section 3, the dynamical direct trust computation function $f_{\text {dir }}$ can be further shown as 


$$
f_{\text {dir }}(t)=T_{e}^{*} T_{c}(t) \frac{e^{\alpha t}-e^{-\alpha t}}{e^{\alpha t}+e^{-\alpha t}}
$$

where values of $T_{e}(t)$ is assumed constant $C$, and $T_{e}(t)$ is relative with service clients. Let $T_{e}(t)$ denote three classical types of service clients, that is risk taking, cautious, and conservative, which can be formulated as

$$
T_{c}(t)=T_{c}=\left\{\begin{array}{l}
H, \text { if } \text { service lient is risk taking } \\
M, \text { if } \text { service lient is cautious } \\
L, \text { if } \text { service lient is conserative }
\end{array}\right.
$$

Concrete values of $H, M$, and $L$ will be discussed in Section 5 .

Lifetime of trust value is also considered in the proposed model. Weight function associated with lifetime is used to construct the time sensitive trust valuation. The more recent trust value has a high weight. Weight function $W(t)$ can be defined as the following exponential function [21]

$$
W(t)=\lambda^{t-t_{0}}
$$

where $\lambda \in(0,1)$ is factor of weight, $t \geq t_{0}$, and $t_{0}$ is reference destination time. The weighted trust value computation function $f_{\text {dir }}$ is as

$$
f_{d i r}(t)=C^{*} T_{c} * \lambda^{\left(t-t_{0}\right)} \frac{e^{\alpha t}-e^{-\alpha t}}{e^{\alpha t}+e^{-\alpha t}}
$$

Parameters of Equation (10) are the same as those in Equations (4) and (7). Consulting with Figure 1, there are total $N$ service-clients, and the reputation evaluation computation formulate $r(t)$ can be shown as

$$
r(t)=\frac{1}{N} \sum_{i=1}^{N} f_{d i r}^{(i)}(t)=\frac{1}{N} \sum_{i=1}^{N} C^{(i)} * T_{c}^{(i)} * \lambda_{(i)}{ }^{\left(t-t_{0}\right)} \frac{e^{\alpha^{(i)} t}-e^{-\alpha^{(i)} t}}{e^{\alpha^{(i)} t}+e^{-\alpha^{(i)} t}}
$$

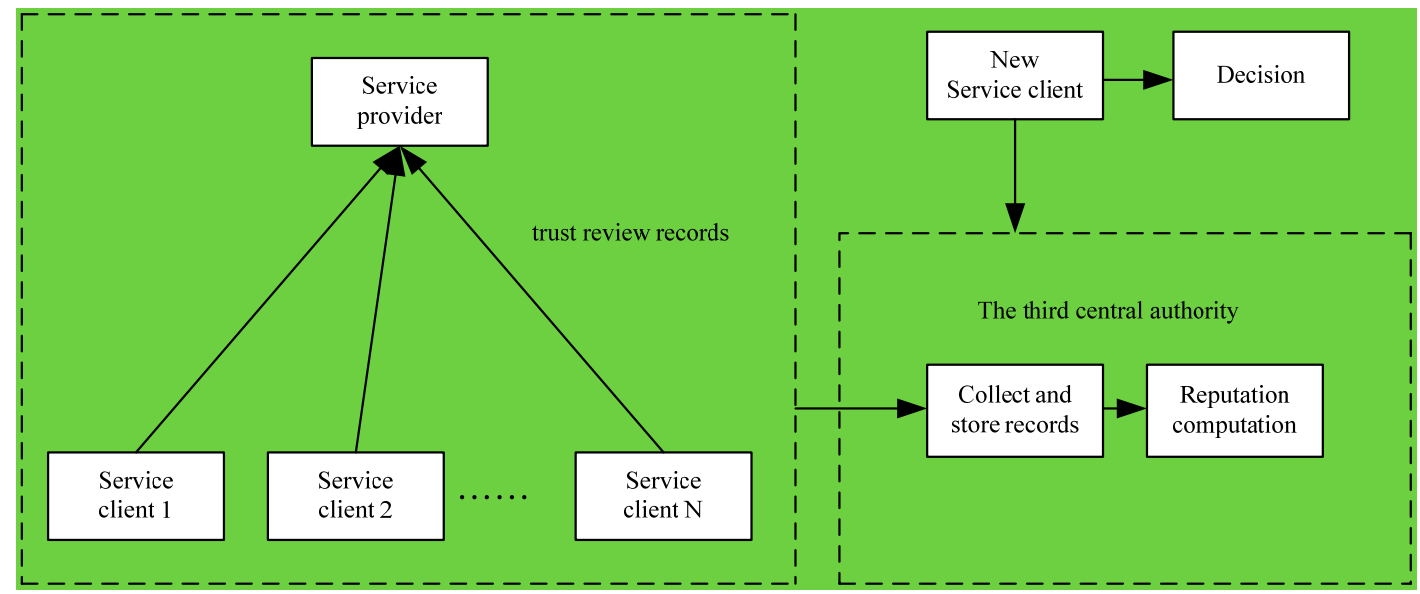

Figure 1. Reputation system in service-oriented networks environments based on trust reviews.

The decrement process of the reputation computation model is similarly shown as

$$
r(t)=\frac{1}{N} \sum_{i=1}^{N} f_{d i r}^{(i)}(t)=\frac{1}{N} \sum_{i=1}^{N} C^{(i)} * T_{c}^{(i)} * \lambda_{(i)}{ }^{\left(t-t_{0}\right)} \frac{e^{-\alpha^{(i)} t}-e^{\alpha^{(i)} t}}{e^{-\alpha^{(i)} t}+e^{\alpha^{(i)} t}}
$$


We see the values of reputations contain dynamical direct trust values from all $N$ service clients. The relationship of direct trust values and the values of reputations will be simulated in Section 5 .

\subsection{Model of Total Trust and Reputation}

Trust in service-oriented network environments such as B2C e-commerce include direct and indirect factors. However, when a new service client or buyer evaluates the trust status of the service provider before making a transaction decision, direct trust and indirect trust factors are not separated. Trust evaluation is as an integral psychological conception. Indirect trust is focused on the reputation of the service providers based on recommendations of the total online service clients, and the computation formulate of reputation is denoted by Equation (11). The reputation system based on the trust reviews is illustrated by Figure 1. There are in total $N$ service clients and one service provider. In order to describe the total trust computation model clearly, we give a discrete difference formulate of total trust, direct trust, and reputation. In the following equations, time variable $t$ is with the unit step such as $t_{i+1}-t_{i}=1, i \in \mathrm{Z}$. At the time $t_{i}$, total trust value and direct trust regarding the service provider from a new service client (denoted $j$ th service client) are denoted as $T^{(j)}\left(t_{i}\right)$ and $f_{d i r}{ }^{(j)}\left(t_{i}\right)$, and $r\left(t_{i}\right)$ denotes reputation value at that time. The integrated quantitative total trust value can be calculated as

$$
T^{(j)}\left(t_{i}\right)=\beta f_{\text {dir }}{ }^{(j)}\left(t_{i}\right)+(1-\beta) r\left(t_{i}\right)
$$

where the weight factor $\beta \in[0,1]$ balances the values of direct trust and reputation values. If $\beta=1$, the total trust value from the new service client will be equal to his direct trust. If $\beta=0$, the total trust value come from the reputation. Equation (10), Equations (11) and (13) give the relation of total trust, direct trust, and reputation value such as

$$
T^{(j)}\left(t_{i}\right)=\beta C^{(j) *} T^{(j)}{ }_{c}\left(t_{i}\right) \frac{e^{\alpha^{(j)} t_{i}}-e^{-\alpha^{(j)} t_{i}}}{e^{\alpha^{(j)} t_{i}}+e^{-\alpha^{(j)} t_{i}}}+(1-\beta) \frac{1}{N} \sum_{l=1}^{N} C^{(l) *} T_{c}^{(l)} * \lambda_{(l)}{ }^{\left(t_{i}-t_{0}\right)} \frac{e^{\alpha^{(l)} t_{i}}-e^{-\alpha^{(l)} t_{i}}}{e^{\alpha^{(l)} t_{i}}+e^{-\alpha^{(l)} t_{i}}}
$$

If Equation (12) is used to simulate the decrement processes of the total trust, the integrated total trust value can be calculated as

$$
T^{(j)}\left(t_{i}\right)=\beta C^{(j)} * T_{c}^{(j)}\left(t_{i}\right) \frac{e^{-\alpha^{(j)} t_{i}}-e^{\alpha^{(j)} t_{i}}}{e^{-\alpha^{(j)} t_{i}}+e^{\alpha^{(j)} t_{i}}}+(1-\beta) \frac{1}{N} \sum_{l=1}^{N} C^{(l)} * T_{c}^{(l)} * \lambda_{(l)}{ }^{\left(t_{i}-t_{0}\right)} \frac{e^{-\alpha^{(l)} t_{i}}-e^{\alpha^{(l)} t_{i}}}{e^{-\alpha^{(l)} t_{i}}+e^{\alpha^{(l)} t_{i}}}
$$

The iterative total trust and reputation model will be further proposed. Total trust values of $j$ th service client at time $t_{i}$ and $t_{i+1}$ are $T^{(j)}\left(t_{i}\right)$ and $T^{(j)}\left(t_{i+1}\right)$, and the reputation values of the service provider at time $t_{i}$ and $t_{i+1}$ are $r\left(t_{i}\right)$ and $r\left(t_{i+1}\right)$, and the $j$ th service client is in the total $N$ service clients. As we see, reputation is the collecting, processing, and aggregating of trustworthy information about the service provider. The role in trust of each service client is to change and sustain the reputation of the service provider. In addition, the service provider earns and retains this trust via his reputation. The reputation of the service provider with the whole range conception is interactive with psychological status of trust. If we assume that the total trust value of the service client has the same derivative with direct trust, the difference form of Equation (3) can be used to calculate the total trust values $T^{(j)}\left(t_{i+1}\right)$ of $j$ th service client by $T^{(j)}\left(t_{i}\right)$ at time $t_{i}$ as 


$$
T^{(j)}\left(t_{i+1}\right)=T^{(j)}\left(t_{i}\right)+C^{(j)} * T_{c}^{(j)}\left(t_{i}\right) *\left(\alpha^{(j)}-\left(\frac{e^{\alpha^{(j)} t_{i}}-e^{-\alpha^{(j)} t_{i}}}{e^{\alpha^{(j)} t_{i}}+e^{-\alpha^{(j)} t_{i}}}\right)^{2}\right)\left(t_{i+1}-t_{i}\right)
$$

The total trust $T^{(j)}\left(t_{i+1}\right)$ at time $t_{i+1}$ is determined by the total trust value $T^{(j)}\left(t_{i}\right)$ at time $t_{i}$ and reputation value $r\left(t_{i}\right)$ at time $t_{i}$. The time variable $t$ has a unit step. The total trust value can be calculated as

$$
T^{(j)}\left(t_{i+1}\right)=\beta\left(T^{(j)}\left(t_{i}\right)+C^{(j)} * T_{c}^{(j)}\left(t_{i}\right)^{*}\left(\alpha^{(j)}-\left(\frac{e^{\alpha^{(j)} t_{i}}-e^{-\alpha^{(j)} t_{i}}}{e^{\alpha^{(j)} t_{i}}+e^{-\alpha^{(j)} t_{i}}}\right)^{2}\right)+(1-\beta) r\left(t_{i}\right)\right.
$$

where the weight factor $\beta \in[0,1]$ balances the values of trust and reputation value at time $t_{i}$.

In real life, the changes of the reputation of a services provider are derived from the psychological trust status of a service client. Therefore, the reputation value of the services provider is updated by the trust values of $N$ service clients. When the mean algorithm is adopted, the iterative reputation computation is shown as

$$
r\left(t_{i+1}\right)=r\left(t_{i}\right)+\frac{1}{N} \sum_{j=1}^{N}\left(T^{(j)}\left(t_{i+1}\right)-T^{(j)}\left(t_{i}\right)\right)
$$

Combining Equations (17) and (18), the iterative trust and reputation computation model is shown as

$$
\left\{\begin{array}{l}
T^{(j)}\left(t_{i+1}\right)=(1-\beta) r\left(t_{i}\right)+\beta\left(T^{(j)}\left(t_{i}\right)+C^{(j)} * T_{c}^{(j)}\left(t_{i}\right) *\left(\alpha^{(j)}-\left(\frac{e^{\alpha^{(j)} t_{i}}-e^{-\alpha^{(j)} t_{i}}}{e^{\alpha^{(j)} t_{i}}+e^{-\alpha^{(j)} t_{i}}}\right)^{2}\right), j=1,2, \ldots, N .\right. \\
r\left(t_{i+1}\right)=r\left(t_{i}\right)+\frac{1}{N} \sum_{j=1}^{N}\left(T^{(j)}\left(t_{i+1}\right)-T^{(j)}\left(t_{i}\right)\right) .
\end{array}\right.
$$

If initial trust values of the total $N$ service clients and parameters of the derivative functions of trust values are given, the trust values of the total $N$ service clients and the reputation of the services provider at the following time can be calculated by using the iterative model Equation (19). Similarly, if the difference form of Equation (5) is used to simulate the decrement processes of total trust values $T^{(j)}\left(t_{i}\right)$ and $r\left(t_{i}\right)$, the iterative total trust and reputation computation model is similarly shown as

$$
\left\{\begin{array}{l}
T^{(j)}\left(t_{i+1}\right)=(1-\beta) r\left(t_{i}\right)+\beta\left(T^{(j)}\left(t_{i}\right)+C^{(j)} * T_{c}^{(j)}\left(t_{i}\right) *\left(-\left(\alpha^{(j)}-\left(\frac{e^{-\alpha^{(j)} t_{i}}-e^{\alpha^{(j)} t_{i}}}{e^{-\alpha^{(j)} t_{i}}+e^{\alpha^{(j)} t_{i}}}\right)^{2}\right)\right), j=1,2, \ldots, N .\right. \\
r\left(t_{i+1}\right)=r\left(t_{i}\right)+\frac{1}{N} \sum_{j=1}^{N}\left(T^{(j)}\left(t_{i+1}\right)-T^{(j)}\left(t_{i}\right)\right) .
\end{array}\right.
$$

Equations (19) and (20) are a set of difference equations with varying coefficients which describe the dynamical processes of trust and reputation in $\mathrm{B} 2 \mathrm{C}$ e-commerce.

\section{Simulations and Discussions}

Simulations of the direct trust model, reputation computation model, and iterative total trust and reputation computation models are shown in this section to illustrate the performance of the proposed model. In the simulations, three classical types of service clients (risk taking, cautious, and conservative) are assumed by concrete values, and the influence of the parameters of these models are discussed. Both improvement and decrement processes of trust and reputation are simulated. 


\subsection{Simulation of Direct Trust}

We mainly simulate the influence of the parameters in the direct trust evaluation model in this subsection. The processes of improvement and decrement of the direct trust evaluation function $f_{\text {dir }}$ with three types of service clients (risk taking, cautious, and conservative) are simulated. Figure 2 shows the processes of improvement of the direct trust function $f_{\text {dir }}$ denoted by Equation (7) and derivative function of $f_{\text {dir }}$ with different values of parameter $\alpha$, where the service client is a cautious type, such as $T_{c}=M=0.5$. Because the value of $T_{e}(t)$ is constant, which denotes environmental factors, $C$ is as 1 in following simulations. Figure 3 shows the processes of a decreasing of direct trust function associated with Equations (5) and (6), where the service client is also a cautious type. Figure 4 compares the processes of improvement and decrement of the direct trust function of three types of service clients (risk taking, cautious, and conservative) denoted as $T_{c}=H=0.8, T_{c}=M=0.5$, and $T_{c}=L=0.2$ when parameter $\alpha$ is 0.04 .

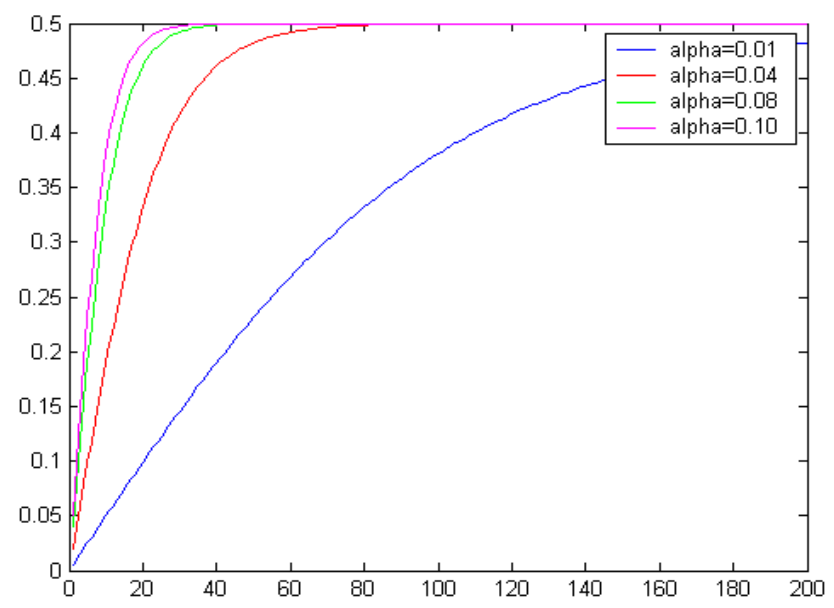

(a)

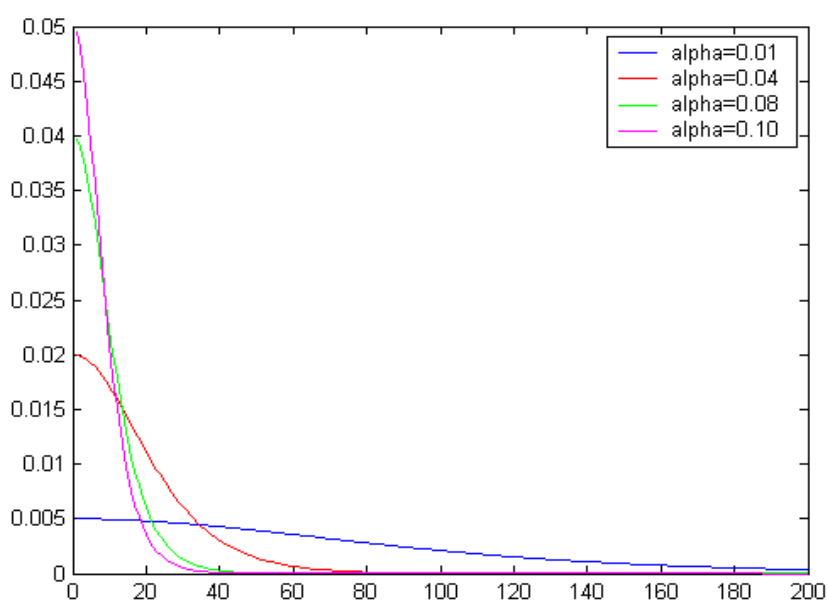

(b)

Figure 2. The processes of improvement of direct trust function. (a) The processes of improvement of direct trust; (b) Derivative functions of direct trust.

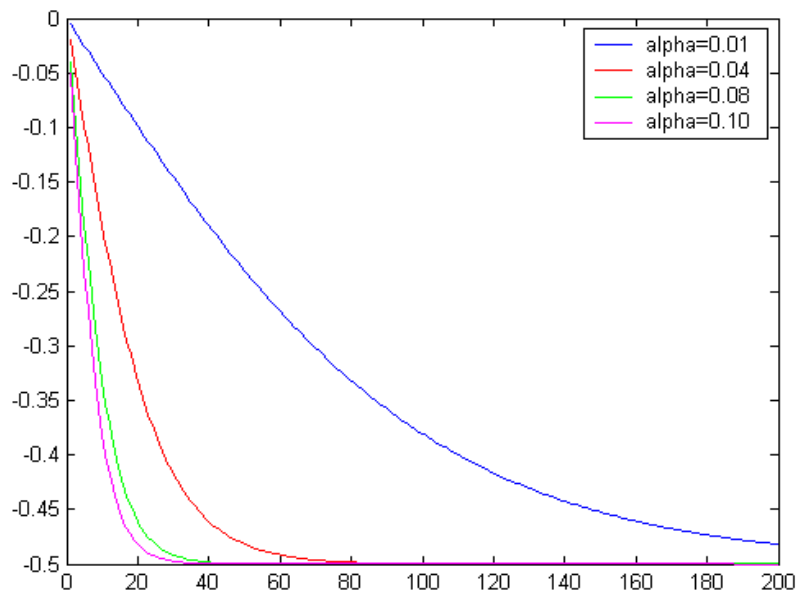

(a)

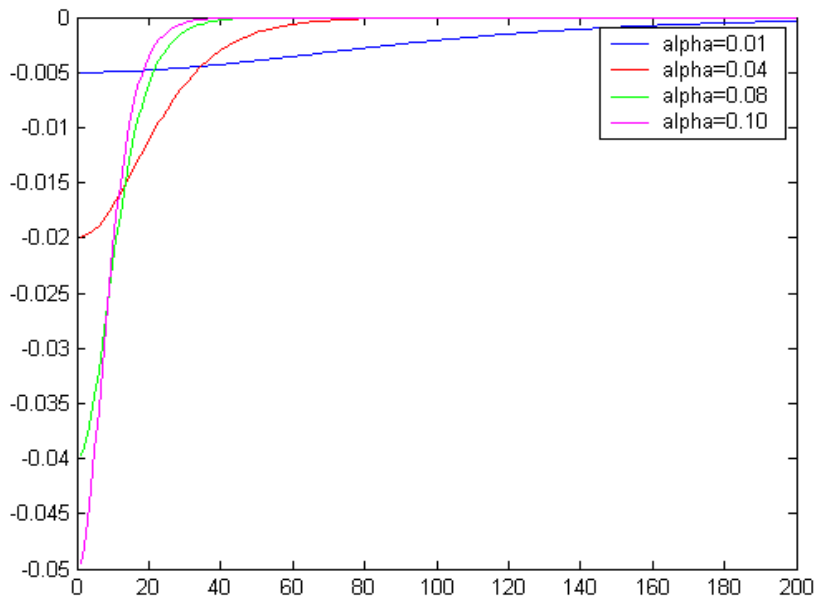

(b)

Figure 3. The processes of decrement of direct trust function. (a) The processes of decrement of direct trust; (b) Derivative functions of direct trust. 


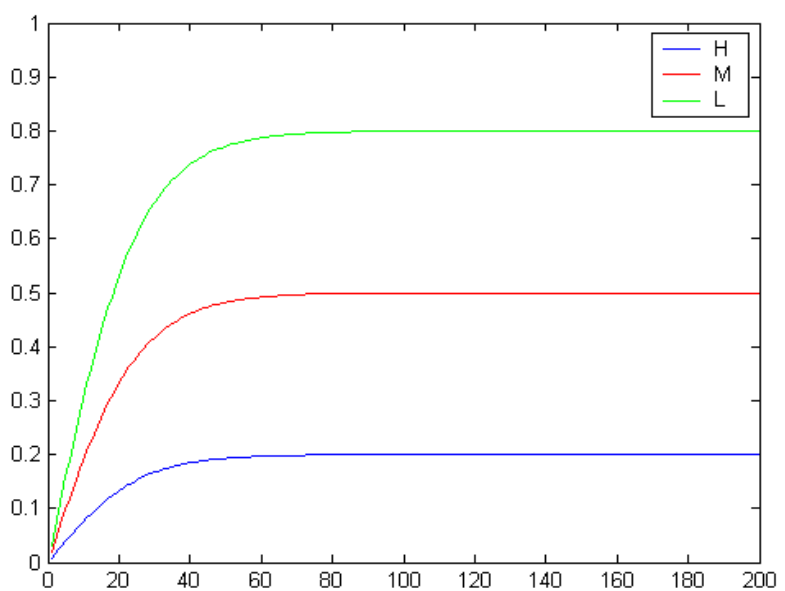

(a)

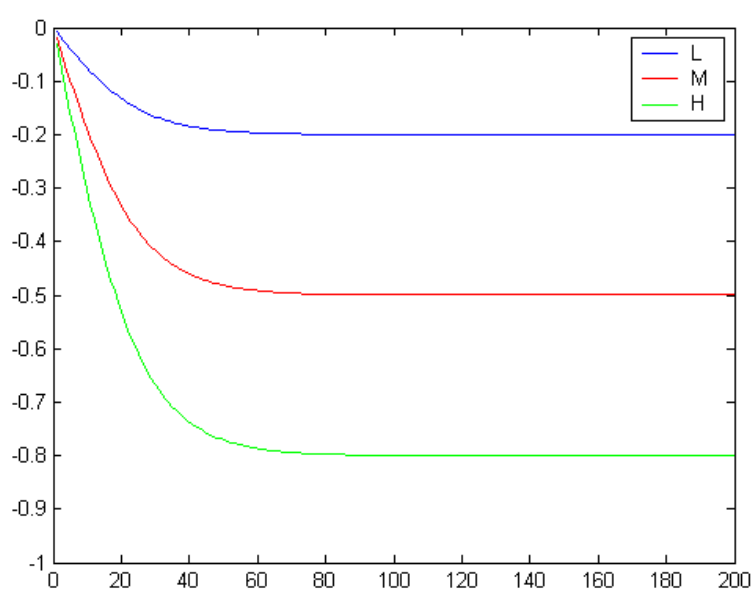

(b)

Figure 4. The processes of improvement and decrement of trust with three types of clients. (a) The processes of improvement of direct trust; (b) The processes of decrement of direct trust.

From Figures 2 and 3, we see that parameter $\alpha$ determines the rates of the processes of improvement and decrement of the direct trust function. If parameter $\alpha$ is bigger, the process of improvement and decrement of the direct trust function is more rapid. The derivative functions of direct trust show that direct trust functions change rapidly in the beginning. Finally, values of derivative functions of the direct trust approach zero. From Figure 4, we see that values of the direct trust function of different types of clients (risk taking, cautious, and conservative) will approach their trust characteristics values, which are denoted as $H, M$ and $L$ in the processes of improvement of direct trust. On the other hand, values of the direct trust function of different types of clients will approach negatives of their trust characteristics values, which are denoted as $-H,-M$ and $-L$ in the processes of the decrement of direct trust. In the former case, risk-taking service clients develop high levels of trust. And in the latter case, risk-taking service clients develop high levels of distrust. Simulation results are consistent with real life.

\subsection{Simulation of the Reputation Computation Model}

In this subsection, the reputation computation model denoted by Equations (11) and (12) is simulated. The influence of weight $\lambda$ on the model is illustrated. Both the processes of improvement and decrement of reputation evaluations are simulated, which contain three types of clients. Figure 5 shows the processes of improvement of the reputation computation model denoted by Equation (11). In Equation (11), $N$ is as 50. In other words, there are a total of 50 direct truth evaluations to combine the values of reputation. Parameter $\alpha^{(i)}$ is the normal distribution as $N(0.04,0.01), i=1,2, \ldots, 50$, and service clients are the cautious type, such as $T_{c}^{(i)}=M=0.5$, and $t_{0}=200$. Figure 6 shows the processes of decrement of the reputation computation model denoted by Equation (12). There are also total of 50 direct truths to combine the values of reputation. Parameter $\alpha^{(i)}$ are also normal distribution as $N(0.04,0.01), i=1,2, \ldots, 50$, and service clients are the risk taking type such as $T_{c}^{(i)}=H=0.8$.

Figure 7 shows the processes of improvement of the reputation computation model by Equation (11), which contain three types of service clients. There are total of 150 direct truth evaluations to combine 
the values of reputation. Each type of service client has 50 direct truth evaluations. Parameter $\alpha^{(i)}$ are normal distribution as $N(0.04,0.01), i=1,2, \ldots, 150$. Values of three types of service clients are normal distributions as $T_{c}=H=N(0.8,0.2), \quad T_{c}=M=N(0.5,0.2) \quad$ and $\quad T_{c}=L=N(0.2,0.2)$. Other parameters remain the same as before.

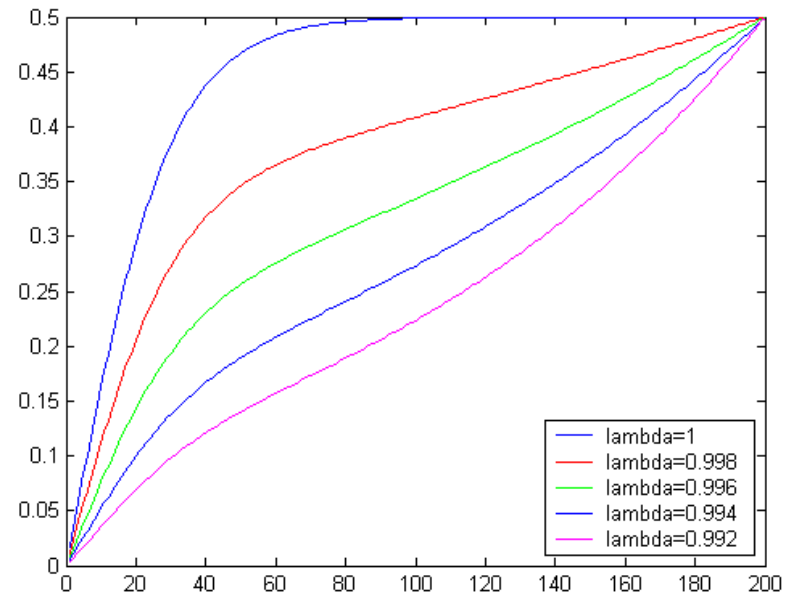

Figure 5. The processes of improvement of the reputation computation model for cautious client type.

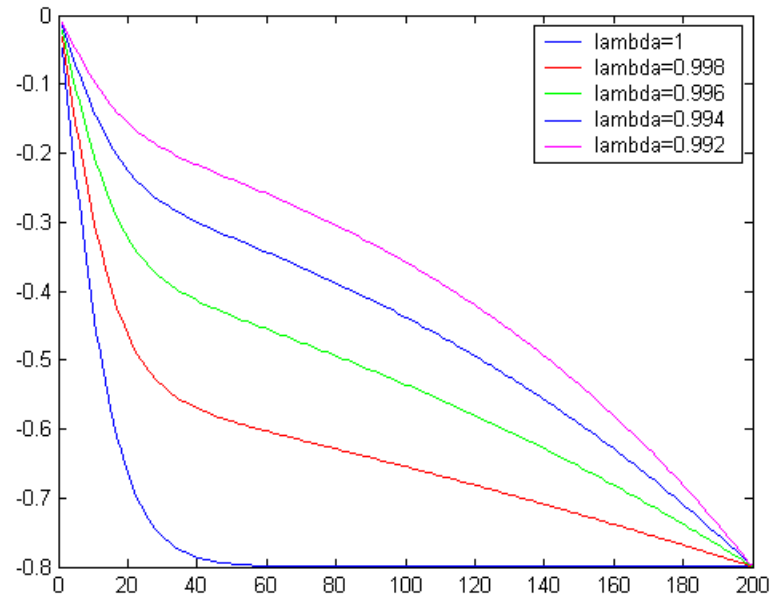

Figure 6. The processes of decrement of the reputation computation model for risk taking client type.

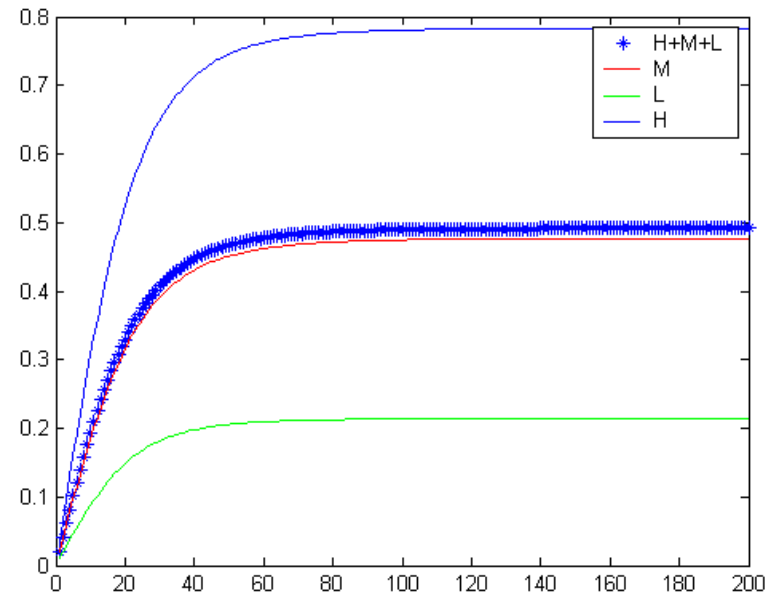

Figure 7. The processes of improvement of the reputation model containing three types of clients. 
Figure 8 shows the processes of decrement of the reputation function denoted by Equation (12) which contain three types of service clients. Parameters and notations are the same as before. In Figures 7 and 8 , the line of cross tar denotes the reputation values that contain 150 service clients of three different types. The blue line denotes the reputation values containing 50 risk-taking clients. The red line denotes the reputation values containing 50 cautious clients. The green line denotes the reputation values containing 50 conservative clients.

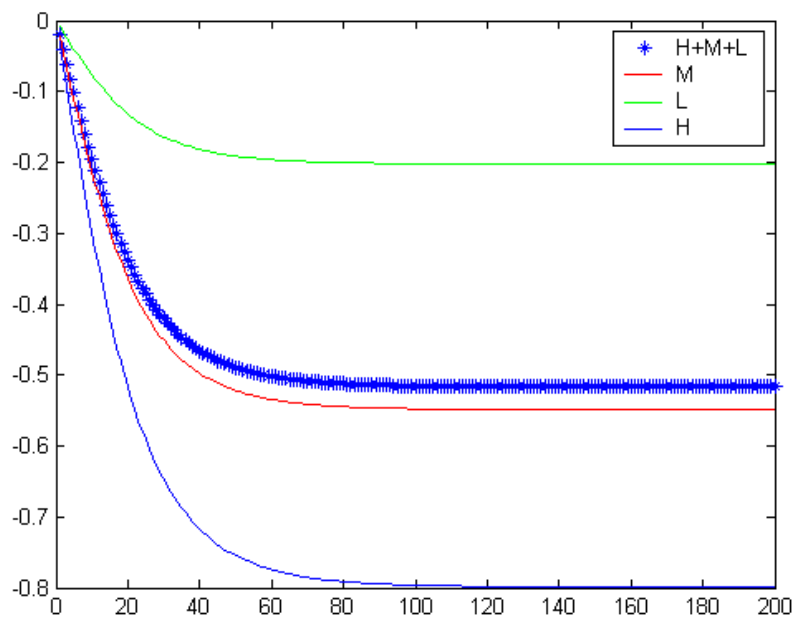

Figure 8. The processes of decrement of the reputation model containing three types of clients.

Form Figures 5 and 6, we see that the values of weight $\lambda$ of Equations (11) and (12) affect the rates of the processes of improvement and decrement of the reputation evaluation when values of parameter $\alpha$ are given. Further, the values of reputation evaluation will approach the trust values of a certain type of client in the processes of the improvement of reputation. The values of the reputation evaluation will approach the negative trust values of a certain type of client in the processes of the decrement of reputation. Figure 7 shows that when all three types of service clients occur in the processes of the improvement of reputation, the values of reputation will approach a positive value. Figure 8 shows that when all three types of service clients occur in the processes of the decrement of reputation, the values of reputation will approach a negative value. Figures 7 and 8 simulate the processes of improvement and decrement of the reputation derived from the direct trust function. Reputation values with different numbers of service clients can also be simulated in similar manner.

\subsection{Simulation of Total Trust Containing Reputation}

In this subsection, total trust containing direct trust and reputation evaluation denoted by Equations (14) and (15) is simulated. Figure 9 shows the processes of improvement of total trust denoted by Equation (14), which contain both direct trust and reputation. There are 50 truth evaluations to combine values of reputation. Parameters $\alpha^{(i)}$ are the normal distribution $N(0.04,0.01), i=1,2, \ldots, 50$, $\lambda=0.998, T_{c}=M=N(0.5,0.2)$. The type of service client is the risk taking type such as $T^{(j)}{ }_{c}=0.8$. Parameters $\alpha^{(j)}$ is 0.05 , and $\beta$ is 0.7 . Figure 10 shows the effect of weight factor $\beta$, which balances the values of direct trust and reputation. 


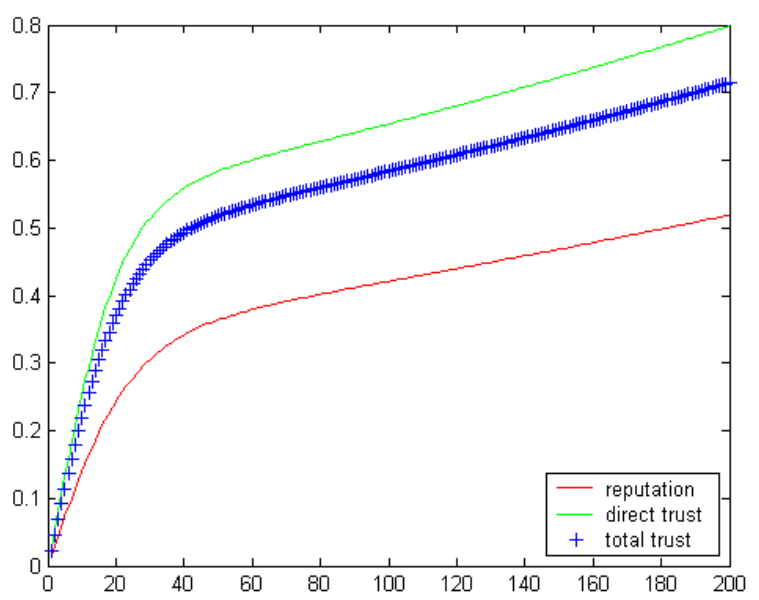

Figure 9. The processes of improvement of total trust values, direct trust values and reputation.

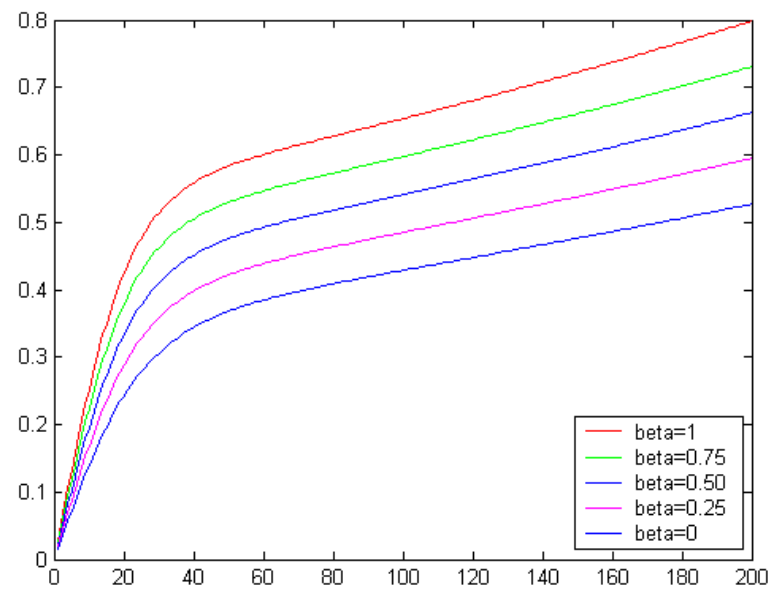

Figure 10. The processes of improvement of total trust values with different values of $\beta$.

Figure 11 shows the processes of the decrement of total trust denoted by Equation (15), which contains direct trust and reputation. Parameters are the same as in Figure 9. Figure 12 shows the processes of change of total trust which contains direct trust and reputation evaluation. Parameters are the same as in Figure 9, however, direct trust is in the processes of improvement, while reputation is falling down.

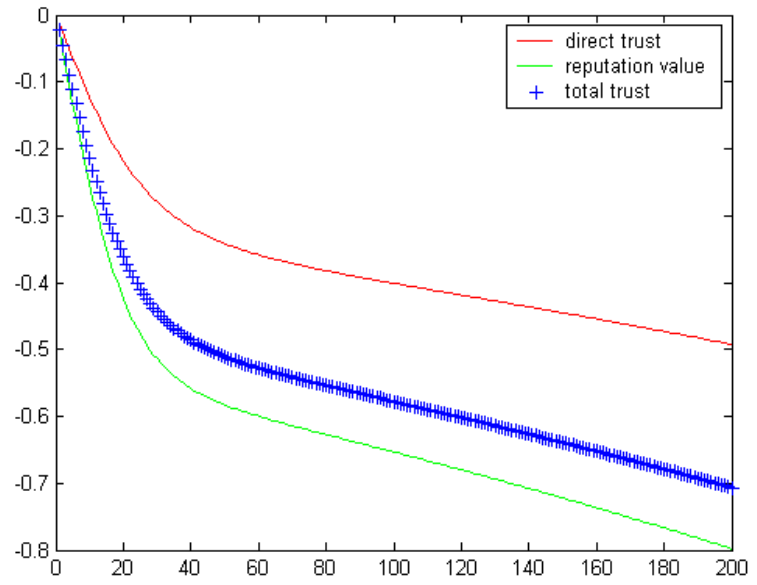

Figure 11. The processes of the decrement of total trust values, direct trust values and reputation. 


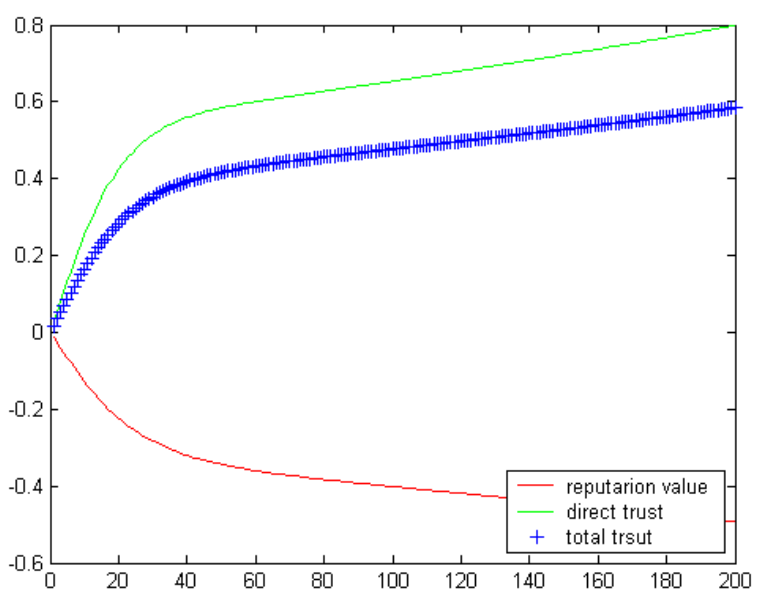

Figure 12. The processes of changes of total trust values with direct trust values and reputation.

From Figure 9 to Figure 12, we see that when direct trust values and reputation values are in the processes of improvement and decrement, they both determine the total trust values. Further, the weight factor $\beta$ balances the values of direct trust and reputation. When other parameters are given, Figure 10 shows the processes of improvement of total trust values with different values of $\beta$. We see values of $\beta$ control the effect of values of direct trust and reputation.

\subsection{Simulation of Iterative Total Trust and Reputation Model}

The iterative total trust and reputation computation model denoted by Equations (19) and (20) is simulated in this subsection. Figure 13 shows the processes of improvement of the iterative reputation model. There are a total of 150 trust evaluations to combine the values of reputation. Parameter $\alpha^{(i)}$ are normal distribution as $N(0.04,0.01), i=1,2, \ldots, 150$. Each type of service client has 50 samples. Initial values of the three types of service clients (risk-taking, cautious, and conservative) are normal distribution as $T_{c}\left(t_{0}\right)=H\left(t_{0}\right)=N(0.8,0.2), \quad T_{c}\left(t_{0}\right)=M\left(t_{0}\right)=N(0.5,0.2) \quad$ and $\quad T_{c}\left(t_{0}\right)=L\left(t_{0}\right) \quad=N(0.2,0.2)$. Parameter $\beta$ is 0.5 , and $r\left(t_{0}\right)$ is the mean value of $T^{(j)}\left(t_{0}\right), j=1,2, \ldots, 150$. In Figure 13, the cross line shows the processes of improvement of reputation evaluation, and the red, green, and blue lines are the typical iterative total trust values of the three types of service clients. Figure 14 shows the processes of the decrement of the iterative reputation model denoted as Equation (20). In Figure 14, the cross line shows the processes of the decrement of reputation, and the red, green, and blue lines are the typical iterative total trust values of the three types of service clients.

From Figure 13, we see that, when the iterative formulation of Equation (19) is used to simulate the processes of improvement of the iterative trust and reputation evaluation, the total trust of the different types of service clients, and the values of reputation will converge to some positive value (0.48 in Figure 13). In other words, the reputation of the service provider will sustain this value stably. Figure 14 shows that when the iterative formulation of Equation (20) is used to simulate the processes of the decrement of iterative trust and reputation, the total trust of different types of service clients and values of reputation will converge to a certain negative value ( -0.44 in Figure 14). Thus, the reputation of the service provider will sustain this value stably. Therefore, the processes of changes in total trust and reputation are reasonably simulated. Values of iterative trust and reputation converge faster than those of the non-iterative trust model denoted by Equation (14). 


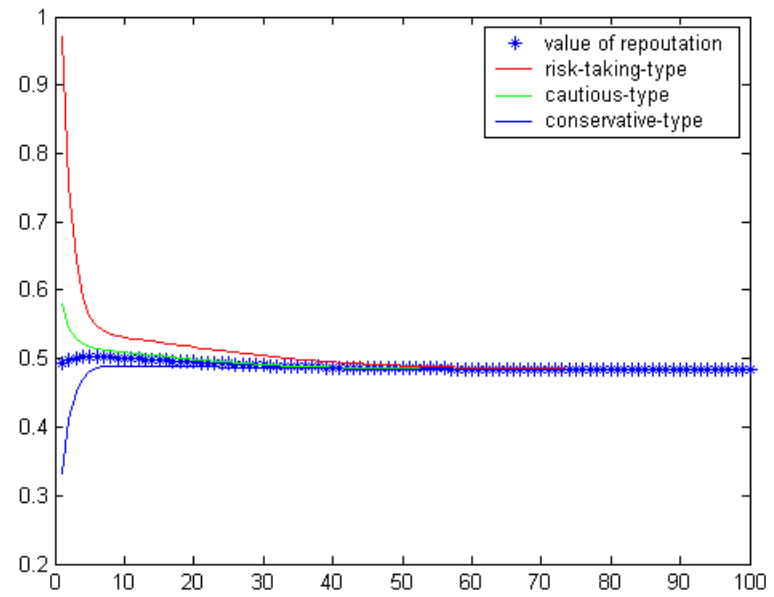

Figure 13. The processes of improvement of the iterative trust and reputation computation model.

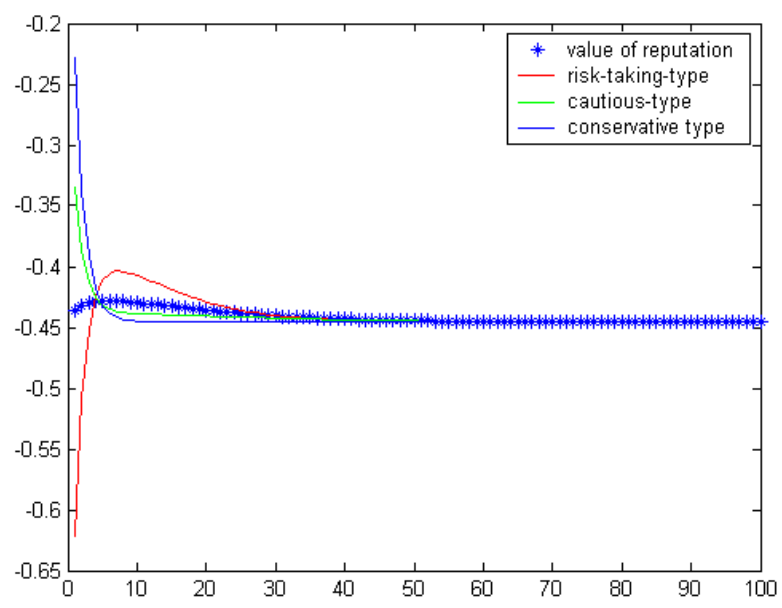

Figure 14. The processes of the decrement of the iterative trust and reputation computation model.

\section{Conclusions}

Trust is one of the most important factors that influence the success of application of Internet services such as B2C e-commerce. The practical trust evaluation systems for B2C e-commerce are based on an open loop relationship of trust and reputation in which reputation is computed by mean of trust. The dynamical closed-loop trust and reputation computation model for $\mathrm{B} 2 \mathrm{C}$ e-commerce in service-oriented network environments has been proposed in this paper. Based on previous related works, characteristics and components of trust for B2C e-commerce have been discussed. Dynamical processes, such as the improvement and decrement of direct trust are simulated via mathematical formulae. Then, the reputation system architecture for $\mathrm{B} 2 \mathrm{C}$ e-commerce is established, and the iterative trust and reputation computation model is further proposed, in which the closed-loop relationship of trust and reputation was consulted. Finally, several groups of simulation experiments were performed to illustrate the proposed models. The main contributions of this paper are as follows:

- $\quad$ Based on our previous work $[23,24,65]$, the conceptions of trust, direct trust, and indirect trust in B2C e-commerce are introduced. The dynamical mathematical model is established to simulate the processes of improvement and decrement of direct trust. 
- The reputation system architecture for B2C e-commerce is established, which is based on the trust records of all service clients. The aggregated reputation computation model that integrates trust values of all service clients is then proposed.

- In order to combine trust values from each service client and with the values of aggregated reputation, the iterative trust and reputation computation model is further proposed for $\mathrm{B} 2 \mathrm{C}$ e-commerce based on the closed-loop relationship of trust and reputation.

- Several groups of numerical simulation experiments are performed to illustrate the proposed model. The processes of improvement and decrement of dynamical direct trust are simulated by Hyperbolic Tangent functions. Three types of service clients, those being risk-taking, cautious, and conservative are expressed numerically. The processes of the changes of direct trust values, total trust values, and reputation are simulated. The processes of improvement and decrement of iterative trust and reputation show that trust values of different types of service clients will converge to the stable value which denotes the reputation of the service provider.

We will further investigate the processes of the changes of trust and reputation by probability theory. We will also verify the proposed model by some practical dataset of service-oriented networks applications such as B2C e-commerce shopping evaluations.

\section{Acknowledgments}

This research is supported by National Natural Science Fund of China (71302080), Shanghai Natural Science Fund (12ZR1409900), Ministry of Education Research of Social Sciences Youth funded projects (13YJC630149), Special Research Found for the Doctoral Program of Higher Education of China (20120078120001) and 2012 Shanghai city young teachers subsidy scheme.

\section{Author Contributions}

All authors have made significant contributions to this paper. Bo Tian carried out the literature review and proposed the trust and reputation computation system. Kecheng Liu and Yuanzhong Chen contributed to the simulation and modification of the manuscript.

\section{Conflicts of Interest}

The authors declare no conflict of interest.

\section{References}

1. Zhang, H.; Wang, Y.; Zhang, X.; Lim, E. ReputationPro: The efficient approaches to contextual transaction trust computation in e-commerce environments. ACM Trans. Web 2015, 9, 1-49.

2. Qin, T.; Liu, X. DSRtrust: A dynamic trust model of distinguishing service and recommendation for internet-based virtual computing environment. Int. J. Grid Distrib. Comput. 2014, 7, 135-147.

3. Iltaf, N.; Ghafoor, A.; Zia, U. A mechanism for detecting dishonest recommendation in indirect trust computation. Eurasip J. Wirel. Commun. Netw. 2013, 189, 1-13. 
4. Jøsang, A.; Ismail, R.; Boyd, C. A survey of trust and reputation systems for online service provision. Decis. Support Syst. 2007, 43, 618-644.

5. Cheung, C.; Lee, M.K.O. Trust in Internet shopping: Instrument development and validation through classical and modern approaches. J. Glob. Inf. Manag. 2001, 9, 23-35.

6. Khirunarayan, K.; Anantharam, P.; Henson, C.; Sheth, A. Comparative trust management with applications: Bayesian approaches emphasis. Future Gener. Comput. Syst. 2014, 31, 182-199.

7. Kim, M.; Park, S.O.H. Trust management on user behavioral patterns for a mobile cloud computing. Clust. Comput. 2013, 16, 725-731.

8. Pinyol, I.; Sabater, M.J. Computational trust and reputation models for open multi-agent systems: A review. Artif. Intell. Rev. 2013, 40, 1-25.

9. Zhang, X.; Cui, L.; Wang, Y. Commtrust: Computing multi-dimensional trust by mining e-commerce feedback comments. IEEE Trans. Knowl. Data Eng. 2014, 26, 1631-1643.

10. Duan, H.; Liu, F. Building and managing reputation in the environment of Chinese e-commerce: A case study on Taobao. In Proceedings of the ACM 2nd International Conference on Web Intelligence, Mining and Semantics WIMS 2012, Craiova, Romania, 13-15 June 2012, pp. 326-333.

11. Clyde, W.H.; Sharath, S. The dynamics of trust in B2C e-commerce: A research model and agenda. Inf. Syst. E-Bus. Manag. 2005, 3, 377-403.

12. Corritore, C.L.; Kracher, B.; Wiedenbeck, S. Online trust: Concepts, evolving themes, a model. Int. J. Hum.-Comput. Stud. 2003, 58, 737-758.

13. Zhang, B.; Huang, Z.; Yu, J.; Xiang, Y. Trust computation for multiple routes recommendation in social network sites. Secur. Commun. Netw. 2014, 7, 2258-2276.

14. Urbano, J.; Rocha, A.P.; Oliveira, E. An approach to computational social trust. AI Commun. 2014, 27, 113-131.

15. Nasir, S.U.; Kim, T.H. Source Fast trust computation in online social networks. IEICE Trans. Commun. 2013, 11, 2774-2783.

16. Yao, L. Mining helpfulness products reviews for $\mathrm{C} 2 \mathrm{C}$ e-commerce. Int. J. Adv. Comput. Technol. 2012, 4, 123-132.

17. Luke, T.W.T.; Michael, L.; Alex, R.; Nicholas, R.J. An efficient and versatile approach to trust and reputation using hierarchical Bayesian model. Artif. Intell. 2012, 193, 149-185.

18. Cho, J.; Kwon, K.; Park, Y. Q-rater, A collaborative reputation system based on source credibility theory. Expert Syst. Appl. 2009, 36, 3751-3760.

19. Wang, Y.; Chung, W.H.; Munindar, P.S. A probabilistic approach for maintaining trust based on evidence. J. Artif. Intell. Res. 2011, 40, 221-267.

20. Liu, X.; Anwitaman, D.; Krzysztof, R. Trust beyond reputation, a computational trust model based on stereotypes. Electron. Commer. Res. Appl. 2013, 12, 24-39.

21. Gutowska, A.; Sloane, A.; Buckley, K.A. On desideratum for B2C e-commerce reputation systems. J. Comput. Sci. Technol. 2009, 24, 820-832.

22. Jøsang, A.; Haller, J. Dirichlet reputation systems. In Proceedings of the Second International Conference on Availability, Reliability and Security (ARES'07), Washington, DC, USA, 13 April 2007; pp. 112-119. 
23. Tian, B.; Wang, J.; Yang, L. Recommended trust evaluation in B2C e-commerce based on fuzzy analytic hierarchy process. Int. J. Knowl. Syst. Sci. 2012, 3, 1-10.

24. Tian, B.; Yang, L. Dynamic reputation model in service-oriented computing environment. In Proceedings of the 2011 International Conference on Transportation, Mechanical, and Electrical Engineering, ChangChun, China, 16-18 December 2011; pp. 933-936.

25. Kant, V.; Bharadwaj, K.K. Fuzzy computational models of trust and distrust for enhanced recommendations. Int. J. Intell. Syst. 2013, 28, 332-365.

26. Egger, F.N. Consumer trust in e-commerce, from psychology to interaction design. In Trust in Electronic Commerce; Prins, J.E.J., Ribbers, P.M.A., van Tilborg, H.C.A., Veth, A.F.L., van der Wees, J.G.L., Eds.; Kluwer Law International: Amsterdam, The Netherlands, 2002; pp. 101-108.

27. Lee, J.; Moray, N. Trust, control strategies, and allocation of functions in human-machine systems. Ergonomics 1992, 35, 1243-1270.

28. Tan, Y.H.; Thoen, W. Toward a generic model of trust for electronic commerce. Int. J. Electron. Commer. 2001, 5, 61-74.

29. McKnight, D.H.; Choudhur, V.; Kacmar, C. Trust in e-commerce vendors, a two-stage model. In Proceedings of the 21 st International Conference on Information Systems, Brisbane, Queensland, Australia, 10-13 December 2000; pp. 532-536.

30. Lee, M.K.O.; Turban, E. A trust model for consumer internet shopping. Int. J. Electron. Commer. 2001, 6, 75-91.

31. China Report on hot events of network (e-mail and Internet shopping, in Chinese). Available online: http://www.ccnic.net.cn. 2015.1.12 (accessed on 21 May 2015).

32. Yeh, Y.S.; Li, Y.M. Building trust in m-commerce, contributions from quality and satisfaction. Online Inf. Rev. 2009, 33, 1066-1086.

33. Gefen, D. Reflections on the dimensions of trust and trustworthiness among online consumers. ACM SIGMIS Database 2002, 33, 38-53.

34. Jarvenpaa, S.; Tractinsky, N.; Vitale, M. Consumer trust in an internet store. Inf. Technol. Manag. J. 2000, 1, 45-71.

35. Krauter, S.G.; Kaluscha, E.A. Empirical research in online trust, a review and critical assessment. Int. J. Hum.-Comput. Stud. 2003, 58, 783-812.

36. Shankar, V.; Urban, G.L.; Sultan, F. Online trust, a stakeholder perspective, concepts, implications, and future directions. J. Strateg. Inf. Syst. 2002, 1, 325-344.

37. Wang, Y.D.; Emurian, H.H. An overview of online trust, concepts, elements, and implications. Comput. Hum. Behav. 2005, 21, 105-125.

38. Bhimani, A. Securing the commerce internet. Commun. ACM 1996, 39, 29-35.

39. Riegelsberger, J.; Sasse, M.A.; McCarthy, J.D. Shiny happy people building trust? Photos on e-commerce websites and consumer trust. In Proceedings of the 2003 Conference on Human Factors in Computing Systems (CHI 2003), Ft. Lauderdale, FL, USA, 5-10 April 2003; Volume 5, pp. 121-128.

40. Ratnasingam, P.; Pavlou, P.A. Technology trust in internet-based interorganizational electronic commerce. J. Electron. Commer. Organ. 2004, 1, 17-41. 
41. Fogg, B.; Tseng, H. The elements of computer credibility. In Proceedings of the SIGCHI Conference on Human Factors in Computing Systems, New York, NY, USA, 1 May 1999; pp. 55-58.

42. Hoffman, D.L.; Novak, T.P.; Peralta, M. Building consumer trust online. Commun. ACM 1999, 42, $80-85$.

43. Li, X.; Ling, L. Peer trust, supporting reputation-based trust for Peer-to-Peer electronic communities. IEEE Trans. Knowl. Data Eng. 2004, 16, 843-857.

44. Huynh, T.D.; Jennings, N.R.; Shadbolt, N.R. An integrated trust and reputation model for open multi-agent systems. J. Auton. Agents Multi-Agent Syst. 2006, 13, 119-154.

45. Ekstrom, M.; Bjonsson, H.; Nass, C. A reputation mechanism for business-to-business electronic commerce that accounts for rater credibility. J. Organ. Comput. Electron. Commer. 2005, 15, 1-18.

46. Zhang, Y.; Chen, H.J.; Jiang, X.H. RCC trust, A combined trust model for electronic community. J. Comput. Sci. Technol. 2009, 24, 883-892.

47. Che, S.; Feng, R.; Liang, X.; Wang, X. A lightweight trust management based on Bayesian and Entropy for wireless sensor networks. Secur. Commun. Netw. 2015, 8, 168-175.

48. Stylianos, K.; Ioannis, N.D.; Angelos, M.; Mohammad, S.O.; Panagiotis, G.S.; Malamati, D.L. A robust reputation-based computational model for trust establishment in pervasive systems. IEEE Syst. J. 2015, 9, 878-891.

49. Kim, D.J.; Song, Y.I.; Braynov, S.B.; Rao, H.R. Multi-dimensional trust formation model in B-to-C e-commerce, a conceptual framework and content analyses of academia/ practitioner perspectives. Decis. Support Syst. 2005, 40, 143-165.

50. McKnighta, D.H.; Choudhury, V.; Kacmar, C. The impact of initial consumer trust on intentions to transact with a web site, a trust building model. J. Strateg. Inf. Syst. 2002, 11, 297-323.

51. Gutowska, A.; Sloane, A. Modelling the B2C marketplace, evaluation of a reputation metric for e-Commerce. Lect. Notes Bus. Inf. Process. 2010, 45, 212-226.

52. Wang, Y.; Lin, K.J.; Wong, D.S. Trust management towards service-oriented applications. Serv. Oriented Comput. Appl. 2009, 3, 129-146.

53. Li, H.H.; Du, X.Y.; Tian, X. A review-based reputation evaluation approach for Web services. J. Comput. Sci. Technol. 2009, 24, 893-900.

54. Adam, W. Trust and Fairness in Open, Distributed Systems. Stud. Comput. Intell. 2010, 298, 11-69.

55. Jordi, S.; Carles, S. Review on computational trust and reputation models. Artif. Intell. Rev. 2005, 24, 33-60.

56. Marsh, S. Formalising Trust as a Computational Concept. Ph.D. Thesis, Department of Mathematics and Computer Science, University of Stirling, Stirling, UK, 1994.

57. Mayer, R.C.; Davis, J.H.; Schoorman, F.D. An integrative model of organizational trust. Acad. Manag. Rev. 1995, 20, 709-734.

58. Jøsang, A.; Hird, S.; Faccer, E. Simulating the effect of reputation systems on e-markets. In Proceedings of the First International Conference on Trust Management, Crete, Greece, 28-30 May 2003, pp. 179-194.

59. Qin, T.; Liu, X. A trust-based resource selection algorithm in Cloud Computing. Comput. Model. New Technol. 2014, 18, 115-121. 
60. Resnick, P.; Zeckhauser, R.; Friedman, E.; Kuwabara, K. Reputation systems. Commun. ACM 2000, $43,45-48$.

61. Huberman, B.A.; Wu, F. The dynamics of reputations. J. Stat. Mech. Theory Exp. 2004, 4, 1-17.

62. Enrique, B.P.; Elena, C.T.; Tomas, E.R. Influence of trust and perceived value on the intention to purchase travel online: Integrating the effects of assurance on trust antecedents. Tour. Manag. 2015, 47, 286-302.

63. Hong, I.B. Understanding the consumer's online merchant selection process: The roles of product involvement, perceived risk, and trust expectation. Int. J. Inf. Manag. 2015, 35, 322-336.

64. Gefen, D.; Karahanna, E.; Straub, D.W. Trust and TAM in online shopping, an integrated model. MIS Q. 2003, 27, 51-90.

65. Zheng, Q.; Tian, B. A trust evaluation model for B2C e-commerce. In Proceedings of the 2007 IEEE/INFORMS International Conference on Service Operations and Logistics, and Informatics, Philadelphia, PA, USA, 27-29 August 2007; pp. 432-437.

(C) 2015 by the authors; licensee MDPI, Basel, Switzerland. This article is an open access article distributed under the terms and conditions of the Creative Commons Attribution license (http://creativecommons.org/licenses/by/4.0/). 